\title{
Metabolic syndrome and its components among obese (BMI $\geq$ 95th) Mexican adolescents
}

\author{
Maria Lola Evia-Viscarra', Edel Rafael Rodea-Montero² , Evelia Apolinar-Jiménez ${ }^{2}$ \\ and Silvia Quintana-Vargas ${ }^{1}$
}

${ }^{1}$ Pediatric Endocrinology Department ${ }^{2}$ Research Department, Hospital Regional de Alta Especialidad del Bajío, Boulevard Milenio 130, San Carlos la Roncha, C.P. 37660 León, Guanajuato, Mexico

\author{
Correspondence \\ should be addressed \\ to E R Rodea-Montero \\ Email \\ edel.rodea@hraeb.gob.mx
}

\begin{abstract}
The aim of this study was to estimate the prevalence of metabolic syndrome (MS) and its components in obese Mexican adolescents and to compare the clinical, anthropometric, and biochemical characteristics between patients with and without MS by sex. We conducted a cross-sectional study with a sample of 110 obese adolescents (boys and girls) from 8 to 16 years old (BMI $\geq 95$ th percentile), who were recruited in the pediatric obesity clinic of a third-level care hospital. A frequency analysis was used to estimate the prevalence of MS and its components, and the assessments were compared between the sexes and between the groups with and without MS using the Kruskal-Wallis test. The prevalence of MS was $62 \%$. In order of prevalence, the following components of MS were observed in the sample: abdominal obesity (88\%), high triglycerides (TG) $(85 \%)$, low HDL-C (60\%), hypertension (35\%), and hyperglycemia (5\%). In the groups with MS, hypertension $(P<0.001)$, waist circumference $(P=0.003)$, and TG $(P=0.012)$ were significantly higher, and HDL-C $(P<0.001)$ was significantly lower. In conclusion the prevalence of MS and its components is high among obese Mexican-Hispanic children. These findings show the importance of preventing and treating obesity in the early stages of life in order to decrease the incidence rates of cardiovascular disease and type 2 diabetes mellitus.
\end{abstract}

\author{
Key Words \\ - adolescents \\ - dyslipidemia \\ - hypertension \\ - metabolic syndrome \\ obesity
}

\section{Introduction}

A sedentary lifestyle and a diet rich in carbohydrates and fats during childhood leads to obesity. In Mexico, the National Health and Nutrition Survey 2012 data estimate a high prevalence of obesity, defined as a BMI $\geq$ the 95 th percentile, at $14.6 \%$ among children (5-11 years) and $13.3 \%$ among adolescents (12-19 years) (1). These prevalence rates are similar to those reported in other high-prevalence countries (2). Pediatric obesity is accompanied by various conditions: orthopedic, respiratory, metabolic (hyperglycemia, dyslipidemia), hepatic (nonalcoholic fatty liver disease), and cardiovascular disease (CVD) (arterial hypertension and vascular dysfunction). The chronic evolution of obesity generates devastating consequences that are associated with long periods of physical incapacity and early mortality (3).

The risk factors for developing CVD and type 2 diabetes mellitus (T2DM) in adults are encompassed by the term 'metabolic syndrome' (MS) (4), which is http://www.endocrineconnections.org DOI: 10.1530/EC-13-0057
(C) 2013 The authors Published by Bioscientifica Ltd
This work is licensed under a Creative Commons Attribution 3.0 Unported License. 
diagnosed based on the criteria of the National Cholesterol Education Program (NCEP) Adult Treatment Panel III (ATP III) (4). Subsequently, these criteria were modified for the pediatric population by obtaining representative values for children. The initial research on the general pediatric population determined that MS may be present in 4.2 to $12.9 \%$ of children. The reported prevalence of MS in obese adolescents ranged from 28.7 to $38.1 \%$, depending on the ethnic group considered or the use of percentiles or absolute value cutoffs to determine the presence of each component of MS $(5,6,7,8)$.

MS is not only a clinical disease precursor but is also currently associated with vascular dysfunction and T2DM in children (9). There is evidence that these risk factors accelerate the development of early atherosclerosis beginning in childhood (10). In both children and adults with obesity and MS, insulin resistance (IR) and chronic inflammation appear to be responsible for the changes that induce complications or comorbidities (11).

In addition, Mexican-Hispanic children are recognized as a high-risk ethnic group (1), which indicates that there will be an increase in the dramatic consequences of obesity (CVD and T2DM) in this population in a few years. Therefore, an investigation of the presence of MS in obese patients in the early stages of life is necessary to plan public health programs for prevention and treatment.

The aim of this study was to estimate the prevalence of MS and its components in obese adolescents and to compare the clinical, anthropometric, and biochemical characteristics between patients with and without MS by sex.

\section{Subjects and methods}

\section{Participants}

We conducted a cross-sectional study with a sample of obese adolescents (boys and girls) from 8 to 16 years old, who were recruited in the Pediatric Obesity Clinic of the third-level Mexican High-Specialty Regional Bajío Hospital (Hospital Regional de Alta Especialidad del Bajío, HRAEB), located in León City in Guanajuato state (México), between April 2008 and December 2012. All of the participants were Mexican-Hispanic and had BMI values $\geq$ the 95th percentile for their age and sex according to the tables published by the Centers for Disease Control and Prevention (CDC). The exclusion criteria were secondary obesity syndromes, obesity associated with the use of medication, and concomitant chronic illnesses.

\section{Approvals}

The protocol for this study was reviewed and accepted by the Research and Ethics Committees of the HRAEB. The patients' parents signed a written consent form when they and their adolescent agreed to enroll.

\section{Clinical assessments}

A complete physical examination was conducted, and blood pressure and pubertal stage according to the Tanner classification were evaluated by a pediatric endocrinologist. Systolic and diastolic blood pressure (SBP and DBP respectively) were taken twice after the participant had been sitting comfortably for $5 \mathrm{~min}$, using a mercury sphygmomanometer (Riester, Jungingen, Germany) with an appropriately sized cuff on the right arm, which was slightly flexed at heart level. The twomeasurement average was used for the analysis. Hypertension (elevated SBP or DBP) was defined as a value that exceeded the 90th percentile for sex, age, and height or the use of anti-hypertensive medication (12).

\section{Anthropometric assessments}

The anthropometric assessments included weight $(\mathrm{kg})$, height $(\mathrm{cm})$, and waist circumference (WC, $\mathrm{cm})$. All of these indicators were evaluated by a pediatric nutritionist. Weight was measured with the children wearing light clothes and no shoes while standing upright at the center of the platform scale. Height was measured using a stadiometer (Seca, Hamburg, Germany) with the children standing in an upright position without shoes, with heels together, their arms extended down on both sides of the body, and their head positioned parallel to the floor. WC was measured using a measuring tape (Seca), at the level of the midpoint between the lower costal border and the iliac crest at the end of a normal expiration (13). Height and WC were measured to the nearest $0.1 \mathrm{~cm}$, and weight was measured to the nearest $0.1 \mathrm{~kg}$. The BMI was calculated by dividing the weight in kilograms by the square of the height in meters. The weight, height, and BMI percentiles were assessed according to the CDC criteria. The WC percentiles were assessed using MexicanHispanic tables for children and adolescents (14).

\section{Biochemical assessments}

The serum samples were processed in an HRAEB Laboratory by the same individual, who had no knowledge

This work is licensed under a Creative Commons Attribution 3.0 Unported License. 
Table 1 Criteria for metabolic syndrome.

\section{Criterion}

High TG level

Low HDL-C level

Abdominal obesity (via WC)

High FPG level

Hypertension

Adults, ATP III
$\geq 1.7 \mathrm{mmol} / \mathrm{l}(\geq 150 \mathrm{mg} / \mathrm{dl})$
Men $\leq 1.1 \mathrm{mmol} / \mathrm{l}(\leq 40 \mathrm{mg} / \mathrm{dl})$
Women $\leq 1.3 \mathrm{mmol} / \mathrm{l}(\leq 50 \mathrm{mg} / \mathrm{dl})$
Men $>102 \mathrm{~cm}$
Women $>88 \mathrm{~cm}$
$\geq 5.6 \mathrm{mmol} / \mathrm{l}(\geq 100 \mathrm{mg} / \mathrm{dl})$
$\mathrm{SBP} \geq 130 \mathrm{mmHg}, \mathrm{DBP} \geq 85 \mathrm{mmHg}$
or using treatment for previously
diagnosed hypertension

Children, ATP III modified by Cruz et al.

$\geq 90$ th percentile (age- and sex-specific)

$\leq 10$ th percentile (age- and sex-specific)

$\geq 90$ th percentile (age-, sex-, and race-specific)

$\geq 5.6 \mathrm{mmol} / \mathrm{l}(\geq 100 \mathrm{mg} / \mathrm{dl})$

$\geq 90$ th percentile (age-, sex-, and height-specific) about the clinical details of the patients. An oral glucose tolerance test (OGTT) was performed following an $8-10 \mathrm{~h}$ fasting period $(1.75 \mathrm{~g} / \mathrm{kg}$, maximum $75 \mathrm{~g}$ anhydrous glucose). The glucose measurements included fasting plasma glucose (FPG) and a 2-h value after the dose of oral glucose. Serum glucose was measured using colorimetric glucose oxidase slides (Vitros 350; Ortho Clinical Diagnostics, Johnson \& Johnson, Raritan, NJ, USA). The interassay coefficient of variation was 3.49 , and the s.D. was $3.04 \%$.

Insulin was determined using an ELISA (Monobind Inc., Lake Forest, CA, USA). The homeostasis model assessment (HOMA) index was calculated as the concentration of fasting insulin $(\mu \mathrm{U} / \mathrm{ml})$ multiplied by the concentration of FPG $(\mathrm{mmol} / \mathrm{l}) / 22.5$, assuming that adolescents have IR when HOMA $\geq 3.16$ (15).

Serum total cholesterol, HDL-C, LDL-C, and triglycerides (TG) were measured using dry chemistry with colorimetric methods (Vitros 350; Ortho Clinical Diagnostics, Johnson \& Johnson).

\section{Definition of MS}

MS in the pediatric population was diagnosed according to the modified ATP III criteria of Cruz et al. (6) using the percentile values for age and sex (Table 1). MS is defined as having at least three of the following five abnormalities: abdominal obesity measured via WC, elevated TG, low HDL-C, hypertension, or if subjects reported current use of any antihypertensive drugs, and hyperglycemia (4). According to the recent recommendation of the American Diabetes Association (ADA), we defined hyperglycemia as an FPG level $\geq 5.6 \mathrm{mmol} / \mathrm{l}$ ( $\geq 100 \mathrm{mg} / \mathrm{dl}$ ), impaired glucose tolerance as a glucose level $\geq 7.8 \mathrm{mmol} / \mathrm{l}(\geq 140 \mathrm{mg} / \mathrm{dl})$ but $<11.1 \mathrm{mmol} / \mathrm{l}$ (200 $\mathrm{mg} / \mathrm{dl}$ ) 2-h after the OGTT, and T2DM as an FPG $\geq 7.0 \mathrm{mmol} / \mathrm{l}$ ( $\geq 126 \mathrm{mg} / \mathrm{dl})$ or $\geq 11.1 \mathrm{mmol} / 1(200 \mathrm{mg} / \mathrm{dl})$ 2-h after the OGTT (16).

\section{Statistical analysis}

All of the data were analyzed using the statistical software R (17). A frequency analysis was used to estimate the prevalence of MS and its components, and the association between MS and sex was also tested using the $\chi^{2}$ test. Descriptive statistics were calculated for the patients' anthropometric and biochemical results. These results were compared between the sexes and between the groups with and without MS using the Kruskal-Wallis test. The sample size allows for the detection of a difference of $\geq 10 \%$ in any assessment (with type I error $\alpha=0.05$ and type II error $\beta=0.80$ ). In all cases, 95\% CIs were constructed, and a statistical significance level of $\alpha=0.05$ was used.

\section{Results}

The final analysis included 110 obese adolescents: 48 (44\%) females and $62(56 \%)$ males. The mean ( \pm s.D.) age of the patients was $11.55 \pm 2.02$ years (range $8.11-15.97$ years). The presence of MS and its components in the study population is shown in Table 2. Overall, the

Table 2 The presence of metabolic syndrome and its components in the study population by sex.

\begin{tabular}{|c|c|c|c|c|}
\hline & $\begin{array}{l}\text { Overall } \\
(n=110)\end{array}$ & $\begin{array}{c}\text { Female } \\
(n=48)\end{array}$ & $\begin{array}{c}\text { Male } \\
(n=62)\end{array}$ & $\begin{array}{l}\text { Inter-group } \\
\text { comparison }^{a}\end{array}$ \\
\hline $\begin{array}{l}\text { Metabolic syn- } \\
\text { drome, } n(\%)\end{array}$ & $68(62 \%)$ & $29(60 \%)$ & $39(63 \%)$ & $P=0.790$ \\
\hline High TG, $n(\%)$ & $94(85 \%)$ & $43(90 \%)$ & $51(82 \%)$ & $P=0.260$ \\
\hline $\begin{array}{l}\text { Low HDL-C, } \\
n(\%)\end{array}$ & $66(60 \%)$ & $28(58 \%)$ & $38(61 \%)$ & $P=0.754$ \\
\hline $\begin{array}{l}\text { Abdominal obesity, } \\
n(\%)\end{array}$ & $97(88 \%)$ & $42(88 \%)$ & $55(89 \%)$ & $P=0.845$ \\
\hline $\begin{array}{l}\text { Hyperglycemia, } \\
n(\%)\end{array}$ & $5(5 \%)$ & $3(6 \%)$ & $2(3 \%)$ & $P=0.450$ \\
\hline $\begin{array}{l}\text { Hypertension, } \\
n(\%)\end{array}$ & $39(35 \%)$ & $18(38 \%)$ & $21(34 \%)$ & $P=0.693$ \\
\hline
\end{tabular}

This work is licensed under a Creative Commons Attribution 3.0 Unported License. 


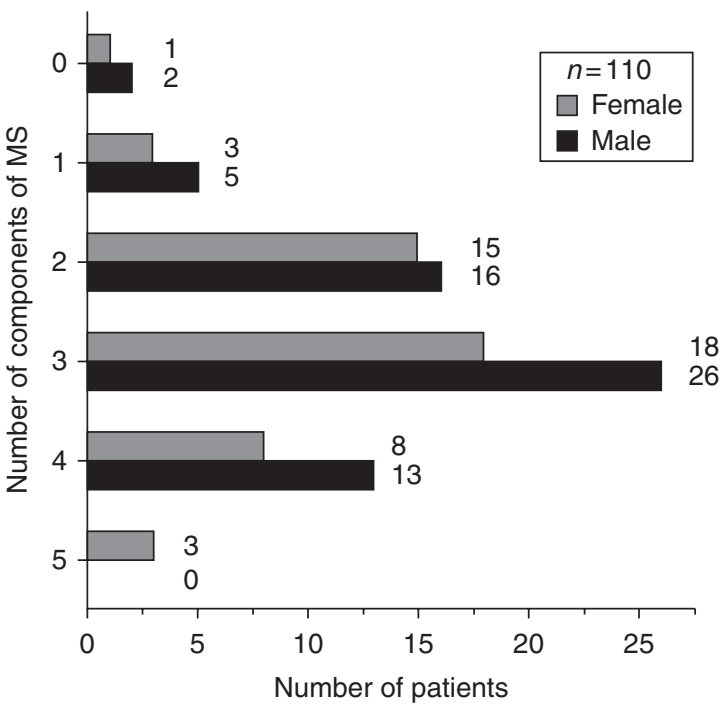

Figure 1

The study patients grouped according to sex and the number of metabolic syndrome components.

prevalence of MS among the patients was $62 \%$. In order of prevalence, the following components of MS were observed in the sample: abdominal obesity (88\%), high TG (85\%), low HDL-C (60\%), hypertension (35\%), and hyperglycemia (5\%). There were no significant differences between males and females for any of the components. In addition, we analyzed a number of the components of MS by sex in detail (Fig. 1) and found that three patients (one female and two males) did not demonstrate any components of MS despite having a BMI $\geq$ the 95th percentile. Another important result was that only three female patients had all the five components of MS.

The patients were divided into four groups by sex and the presence $(+)$ or absence $(-)$ of MS. The clinical and anthropometric measurements are shown in Table 3. Based on the inter-group comparison, the ages of the groups appeared to be similar $(P=0.802)$, indicating that the groups were homogenous with regard to age. The median Tanner classification was significantly different $(P<0.001)$ between the females (median Tanner score of 3 ) and males (median Tanner score of 2 ). The SBP and DBP values were significantly higher $(P<0.001$ in both cases) in the groups with MS. There were apparent but not significant differences in the BMI $(P=0.054)$ and BMI percentile $(P=0.054)$ between the patients with and without MS. Weight was significantly higher in the groups with MS $(P=0.023)$. Height was significantly higher in the groups with MS $(P=0.043)$. There were also significant differences in the WC $(P=0.003)$ : the patients with MS had higher values.

Table 4 illustrates the biochemical characteristics of the study population. There was no evidence of differences among the groups in the glucose metabolism assessments. The mean FPG and 2-h glucose values appeared to be similar and unaltered across all groups $(P=0.325$ and $P=0.180$, respectively). The adolescents with MS, especially the females, had slightly higher serum insulin

Table 3 Clinical and anthropometric characteristics of the study population grouped by sex and the presence of metabolic syndrome.

\begin{tabular}{|c|c|c|}
\hline & & Female \\
\hline & Overall $(n=110)$ & $\begin{array}{l}\text { Without MS }(-) \\
\quad(n=19)\end{array}$ \\
\hline \multicolumn{3}{|l|}{ Clinical } \\
\hline Female, $n(\%)$ & $48(44 \%)$ & \\
\hline Male, $n(\%)$ & $62(56 \%)$ & \\
\hline Age (years) & $11.55(2.02)$ & $11.54(2.6)$ \\
\hline Tanner (median) & 2 & 3 \\
\hline $\mathrm{SBP}(\mathrm{mmHg})$ & $111.11(10.43)$ & $107.11(6.52)$ \\
\hline $\mathrm{DBP}(\mathrm{mmHg})$ & $65.51(9.54)$ & $63.16(8.85)$ \\
\hline \multicolumn{3}{|l|}{ Anthropometric } \\
\hline Weight (kg) & $70.26(19.25)$ & $65.19(17.29)$ \\
\hline Height $(\mathrm{cm})$ & $149.89(11.6)$ & $147.04(10.75)$ \\
\hline BMI $\left(\mathrm{kg} / \mathrm{m}^{2}\right)$ & $30.6(5.3)$ & $29.62(5.49)$ \\
\hline BMI percentile & $98.49(1.04)$ & $98.27(0.95)$ \\
\hline WC $(\mathrm{cm})$ & $93.76(11.43)$ & $87.35(8.84)$ \\
\hline
\end{tabular}

\begin{tabular}{l}
$11.84(1.92)$ \\
3 \\
$113.41(7.77)$ \\
$70.48(8.67)$ \\
$75.28(20.19)$ \\
$152.34(10.55)$ \\
$31.77(5.22)$ \\
$98.54(1.18)$ \\
$95.49(11.15)$ \\
\hline
\end{tabular}

\begin{tabular}{cc}
\hline \multicolumn{2}{c}{ Male $(n=62)$} \\
\hline $\begin{array}{c}\text { Without MS }(-) \\
(n=23)\end{array}$ & With MS (+) \\
$(n=39)$
\end{tabular}

Inter-group comparison

Unless otherwise indicated, the values are given as the mean (s.D.).

${ }^{a}$ Kruskal-Wallis test with three degrees of freedom.

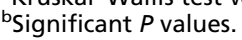

$$
\begin{aligned}
& \text { http://www.endocrineconnections.org } \\
& \begin{array}{lr}
\text { DOI: } 10.1530 / E C-13-0057 & 2013 \text { The authors } \\
\end{array}
\end{aligned}
$$

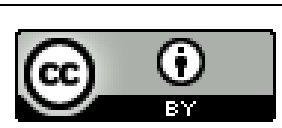

This work is licensed under a Creative Commons Attribution 3.0 Unported License. 


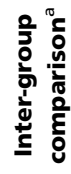

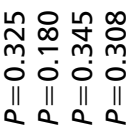

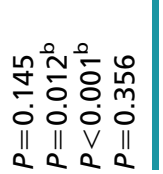

$$
\text { II }
$$

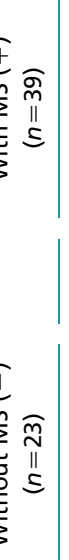<smiles>[Fe]=C=[Ge]</smiles>

ํํ웜

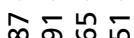

ช่ $\operatorname{x} m$

ஸ

II

สิธิธิธิธู

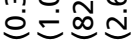

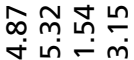

的宁

ก

$\stackrel{\text { II }}{=}$

$\widehat{\text { กิ }}$

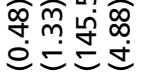

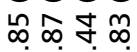

ช่ กี่

$\stackrel{\infty}{1}$
$\stackrel{\infty}{\Sigma}$

ิㅗํํํㅇํㅇ

巳巳巳

도ำ

กิ่ํํำ

อうo

సิํำ

$m$

$\stackrel{m}{\stackrel{\infty}{1}}$

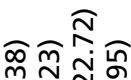

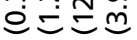

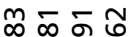

ช่ เก่ $\ln \mathrm{m}$

Aं $\dot{n}$

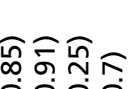

อยอ

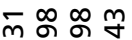

ச-

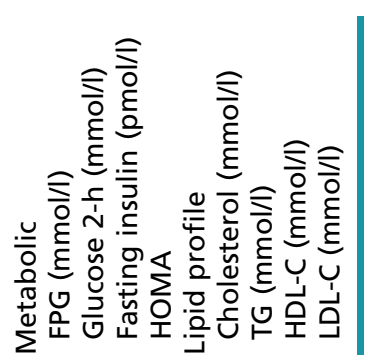

http://www.endocrineconnections.org DOI: 10.1530/EC-13-0057
(C) 2013 The authors Published by Bioscientifica Ltd concentrations, although no significant differences were detected $(P=0.345)$. With regard to HOMA values, there were no significant differences among the four groups; however, the MS groups presented values above normal, indicating that these patients had some degree of IR, especially the adolescent females with MS. With regard to the lipid profile, there were no significant differences among the groups in their cholesterol and LDL-C levels. The comparisons of TG showed significantly higher $(P=0.012)$ values in the patients with MS, particularly the females. HDL-C was significantly lower in the MS groups $(P<0.001)$.

\section{Discussion}

Most studies published in the literature on MS in the pediatric population compare normal-weight, overweight (85th $\leq$ BMI $<95$ th), and obese (BMI $\geq 95$ th) children. This study analyzed the presence of the components of MS specifically in obese adolescents and excluded normalweight or overweight children. Therefore, this work, unlike most studies on pediatric MS, enables a comparison of obese adolescents with and without MS who share similar lifestyles and dietary habits.

The ages of the participants were not significantly different among the groups. Overall, the children were in puberty, but the girls showed more advanced Tanner stages, most probably because females start puberty at an earlier age than males. This difference could also be related to the fact that excess adiposity in girls may influence the early onset of puberty, as some authors have suggested (18).

Previous studies appeared to show a greater prevalence of MS among males. Our study did not find significant differences in the presence of MS or its components between males and females, which could be related to the different Tanner stages.

The estimated prevalence of MS in this study was $62 \%$, higher than the global reports that have estimated the prevalence between at 28.7 and $30.7 \%$ among children with obesity $(5,19)$ and between at 30 and $35.8 \%$ in groups in which overweight and obese children are combined (5, $6,7,20)$. Our results are similar to the results of studies conducted in Mexican populations; for example, the study by Elizondo-Montemayor et al. (21) reported that the prevalence of MS based on BMI $Z$-scores ranged from 42.6 $(2<Z \leq 2.5)$ to $73.6 \%(Z>2.5)$. In comparison, we found a prevalence of $79.2 \%$ among the patients whose BMI $Z$-score was $>2.5$. In accordance with a study conducted in the United States of America among Mexican-American

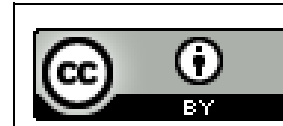

This work is licensed under a Creative Commons Attribution 3.0 Unported License. 
children, our population had a high prevalence of MS and therefore high cardiovascular metabolic risk (5).

In our study, three of the children did not show any components of MS, even though their BMI values indicated the presence of obesity. This result makes us question whether BMI is a predictor of MS for all obese pediatric patients. We used the WC reference tables developed specifically for the Mexican population by Klunder-Klunder \& Flores-Huerta (14), and when we compared the 90th percentile of WC with the proposals in the study of Fernández et al. (22), we found that the concordance was $>95 \%$. Central obesity was significantly more common in the MS groups, supporting the observation that $\mathrm{WC}$ is a better predictor of MS than BMI. Lee et al. showed that there is a strong correlation among WC, dyslipidemia, and hypertension. This correlation is associated with increased abdominal visceral fat metabolism, which appears to promote lipid disorders and IR, two factors that are responsible for the deleterious effects of obesity (23).

The prevalence of hypertriglyceridemia in obese children with MS was very high compared with worldwide studies on adolescents $(6,7)$ and even compared with other studies on Hispanic populations (85 vs $20-30 \%$ ) (20). The prevalence of low HDL-C in the groups with MS is similar to the prevalence reported in other studies (50 vs $53.7 \%)(6,20)$.

Hypertriglyceridemia combined with low HDL-C levels has been strongly linked with the presence of IR (24) and is associated with increased central adipose tissue (25). In this study, we observed that the patients with MS had greater WC than the obese adolescents without MS. Some authors have proposed that there is a strong association between TG/HDL-C and IR in adolescents and that this indicator could be used to assess the CVD risk in obese children (26). Autopsy studies and vascular function studies (27) in obese children have strongly indicated that abnormal lipid levels are associated with an increased incidence of atherosclerosis.

Dyslipidemia among the children with MS in this study can be attributed not only to a genetic predisposition but also to the typical diet in this country.

The prevalence of hypertension in our study population was higher than that in other studies (35 vs $20.6 \%$ ) (20). Some studies have identified hypertension in obese children as the factor that is responsible for the genesis of atherosclerosis, vascular dysfunction, CVD, and premature death $(3,28,29)$.

The insulin levels were slightly but not significantly higher in the groups with MS, but the mean glucose level (before and after OGTT) was normal. The mean insulin level was $>104.18 \mathrm{pmol} / \mathrm{l}(15 \mu \mathrm{IU} / \mathrm{ml})$, with wide variability; this value was proposed as an indicator of IR by Reaven (30). The HOMA index was also higher in the MS groups, especially in the girls (HOMA $>4$ ). Currently, there is no consensus on the appropriate HOMA cutoff for defining IR in adolescents. Keskin et al. (31) defined IR as a HOMA value $\geq 3.6$, but recently, some authors $(32,33)$ have preferred to use the cutoff of 3.16 for predicting MS, as suggested by Tresaco et al. (15). The insulin sensitivity is abnormal for all of the subjects in our study population, considering that the HOMA level in normal young people is close to 1 (34).

The frequency of hyperglycemia in this study was lower than the frequency observed by Shaibi \& Goran (5 vs $25.2 \%$ ) in a Hispanic population (20) and even lower than those reported among Mexican groups (35). This low prevalence may be attributed to the fact that our patients had previously been evaluated in a primary care office; diabetes mellitus is usually scrutinized carefully in all obese patients given the alarming growth of T2DM in Mexican children (36). However, this prevalence of hyperglycemia, although relatively low compared with the other components of MS, indicates that the compensatory mechanism caused by hyperinsulinism is no longer sufficient and that pancreatic function deteriorates in the early stages of life. Thus, prospective studies of MS in children should be performed to elucidate the risk factors and the time needed for their condition to lead to the deterioration of pancreatic $\beta$-cell function. Some authors consider MS to be a poor predictor of T2DM (37) and even suggest that haemaglobin A1c may be a more sensitive indicator to predict the loss of pancreatic function (38). Based on this reasoning, the MS components should not be evaluated in a dichotomous way; instead, each component should be studied to determine its possible value for predicting CVD or T2DM.

Moreover, there are no unified worldwide criteria for determining the presence of MS in children. Although the International Diabetes Federation Workshop (39) tried to unify the criteria, it only considered children older than 10 years and created absolute values for each of the parameters. We found it difficult to follow these recommendations because this approach would limit research on obese children under 10 years old, a group that could experiences complications $(9,40)$. Using the ATP III criteria modified by Cruz et al. (6) allowed us to stratify each component and better evaluate our population.

This study has certain limitations. It was a crosssectional study, and thus, causality cannot be inferred.

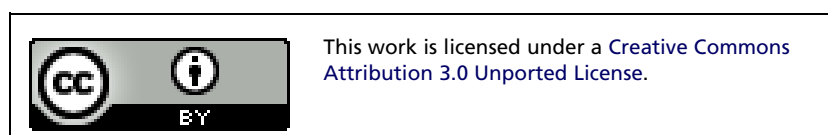


The subjects in this study were not recruited from the general population; they were referred to our center because they were identified as a high-risk population in primary and secondary health care offices. This sample consisted of Mexican children, which may limit its generalizability to other ethnic groups. Some critics might suggest that the study lacks a control group of healthy children. However, the goal of our study was to assess the presence of MS and its components in obese children with increased metabolic risk to pay specific attention to them and to design more effective treatment measures.

\section{Conclusion}

Our study showed that the prevalence of MS is high among obese Mexican-Hispanic children. A large WC, which influences the changes in TG, HDL-C, and arterial hypertension, is particularly common. In the coming years, this alteration will lead to increases in the incidence rates of CVD and T2DM in our country. Therefore, the high prevalence of MS in obese children shows the importance of preventing and treating obesity in a timely manner beginning in the early stages of life. Our results also indicate that hypertriglyceridemia is highly prevalent among children with obesity and MS in this ethnic group. Further studies are required to assess the etiology, evolution, and consequences of this alteration.

\section{Declaration of interest}

The authors declare that there is no conflict of interest that could be perceived as prejudicing the impartiality of the research reported.

\section{Funding}

This research did not receive any specific grant from any funding agency in the public, commercial or not-for-profit sector.

\section{Acknowledgements}

The authors wish to thank all the patients and staff who participated in the study.

\section{References}

1 Gutierrez JP, Rivera Dommarco J, Shamah Levy T, Villalpando Hernández S, Franco A, Cuevas Nasu L, Romero Martínez M \& Hernández Ávila M. 2012 Resultados Nacionales. Cuernavaca, México: Encuesta Nacional de Salud y Nutrición.

2 de Onis M, Blössner M \& Borghi E. Global prevalence and trends of overweight and obesity among preschool children. American Journal of Clinical Nutrition 201092 1257-1264. (doi:10.3945/ajcn.2010.29786)
3 Franks PW, Hanson RL, Knowler WC, Sievers ML, Bennett PH \& Looker HC. Childhood obesity, other cardiovascular risk factors, and premature death. New England Journal of Medicine 2010362 485-493. (doi:10.1056/NEJMoa0904130)

4 National Cholesterol Education Program (NCEP) Expert Panel on Detection, Evaluation, and Treatment of High Blood Cholesterol in Adults (Adult Treatment Panel III). Third Report of the National Cholesterol Education Program (NCEP) Expert Panel on Detection, Evaluation, and Treatment of High Blood Cholesterol in Adults (Adult Treatment Panel III) final report. Circulation 20021063143.

5 Cook S, Weitzman M, Auinger P, Nguyen M \& Dietz WH. Prevalence of a metabolic syndrome phenotype in adolescents: findings from the third National Health and Nutrition Examination Survey, 1988-1994. Archives of Pediatrics \& Adolescent Medicine 20032003 821-827. (doi:10.1001/archpedi.157.8.821)

6 Cruz M, Weigenserg M, Ball G, Shaibi G \& Goran M. The metabolic syndrome in overweight Hispanic yougth and the role of insulin sensitivity. Journal of Clinical Endocrinology and Metabolism 200489 108-113. (doi:10.1210/jc.2003-031188)

7 de Ferranti SD, Gauvreau K, Ludwig DS, Neufeld EJ, Newburger JW \& Rifai N. Prevalence of the metabolic syndrome in American adolescents: findings from the Third National Health and Nutrition Examination Survey. Circulation 2004110 2494-2497. (doi:10.1161/01.CIR. 0000145117.40114.C7)

8 Weiss R, Sziura J, Burgert T, Tamborlane W \& Taksali S. Obesity and the metabolic syndrome in children and adolescents. New England Journal of Medicine 2004350 2362-2374. (doi:10.1056/NEJMoa031049)

9 Liese AD, D'Agostino RB Jr, Hamman RF, Kilgo PD, Lawrence JM, Liu LL, Loots B, Linder B, Marcovina S, Rodriguez B et al. The burden of diabetes mellitus among US youth: prevalence estimates from the SEARCH for Diabetes in Youth Study. Pediatrics 2006118 1510-1518. (doi:10.1542/ peds.2006-0690)

10 Beauloye V, Zech F, Tran HP, Clapuyt P \& Maes M. Determinants of early atherosclerosis in obese children and adolescents. Journal of Clinical Endocrinology and Metabolism 200792 3025-3032. (doi:10.1210/ jc. 2007-0619)

11 Herder C, Schneitler S, Rathmann W, Haastert B, Schneitler H, Winkler H, Bredahl R, Hahnloser E \& Martin S. Low-grade inflammation, obesity, and insulin resistance in adolescents. Journal of Clinical Endocrinology and Metabolism 200792 4569-4574. (doi:10.1210/jc. 2007-0955)

12 National High Blood Pressure Education Program Working Group on High Blood Pressure in Children and Adolescents. The Fourth Report on the Diagnosis, Evaluation, and Treatment of High Blood Pressure in Children and Adolescents. Pediatrics 2004114 555-576. (doi:10.1542/ peds.2004-0347Z)

13 McCarthy HD, Jarrett KV, Emmett PM \& Rogers I. Trends in waist circumferences in young British children: a comparative study. International Journal of Obesity 200529 157-162. (doi:10.1038/ sj.ijo.0802849)

14 Klunder-Klunder M \& Flores-Huerta S. Waist circumference values according to height percentiles: a proposal to evaluate abdominal obesity in Mexican children and adolescents between 6 and 16 years of age. Archives of Medical Research 201142 515-522. (doi:10.1016/ j.arcmed.2011.09.004)

15 Tresaco B, Bueno G, Pineda I, Moreno LA, Garagorri JM \& Bueno M. Homeostatic model assessment (HOMA) index cut-off values to identify the metabolic syndrome in children. Journal of Physiology and Biochemistry 200561 381-388. (doi:10.1007/BF03167055)

16 American Diabetes Association. Diagnosis and classification of diabetes mellitus. Diabetes Care 201235 S64-S71. (doi:10.2337/dc12-s064)

17 R Development Core Team. 2006 A language and environment for statistical computing. Vienna, Austria: Foundation for Statistical Computing.

18 Roemmich JN, Clark PA, Lusk M, Friel A, Weltman A, Epstein LH \& Rogol AD. Pubertal alterations in growth and body composition. VI. Pubertal insulin resistance: relation to adiposity, body fat distribution

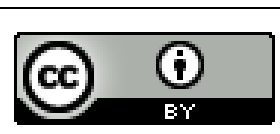


and hormone release. International Journal of Obesity and Related Metabolic Disorders 200226 701-709. (doi:10.1038/sj.ijo.0801975)

19 Andrabi SM, Bhat MH, Andrabi SR, Kamili MM, Imran A, Nisar I \& Nisar U. Prevalence of metabolic syndrome in 8-18-year-old schoolgoing children of Srinagar city of Kashmir India. Indian Journal of Endocrinology and Metabolism 201317 95-100. (doi:10.4103/2230-8210. 107812)

20 Shaibi GQ \& Goran MI. Examining metabolic syndrome definitions in overweight Hispanic youth: a focus on insulin resistance. Journal of Pediatrics 2008152 171-176. (doi:10.1016/j.jpeds.2007.08.010)

21 Elizondo-Montemayor L, Serrano-Gonzalez M, Ugalde-Casas PA, Bustamante-Careaga H \& Cuello-Garcia C. Waist-to-height: cutoff matters in predicting metabolic syndrome in Mexican children. Metabolic Syndrome and Related Disorders 20119 183-190. (doi:10.1089/ met.2010.0116)

22 Fernández JR, Redden DT, Pietrobelli A \& Allison D. Waist circumference percentiles in nationally representative samples of African-American, European-American, and Mexican-American children and adolescents. Journal of Pediatrics 2004145 439-444. (doi:10.1016/j.jpeds.2004.06.044)

23 Lee S, Bacha F, Gungor N \& Arslanian SA. Waist circumference is an independent predictor of insulin resistance in black and white youths. Journal of Pediatrics 2006148 188-194. (doi:10.1016/j.jpeds. 2005.10.001)

24 Steinberger J, Moorehead C, Katch V \& Rocchini AP. Relationship between insulin resistance and abnormal lipid profile in obese adolescents. Journal of Pediatrics 1995126 690-695. (doi:10.1016/ S0022-3476(95)70394-2)

25 Freedman DS, Mei Z, Srinivasan SR, Berenson GS \& Dietz WH. Cardiovascular risk factors and excess adiposity among overweight children and adolescents: the Bogalusa Heart Study. Journal of Pediatrics 2007150 12-17. (doi:10.1016/j.jpeds.2006.08.042)

26 Giannini C, Santoro N, Caprio S, Kim G, Lartaud D, Shaw M, Pierpont B $\&$ Weiss R. The triglyceride-to-HDL cholesterol ratio: association with insulin resistance in obese youths of different ethnic backgrounds. Diabetes Care 201134 1869-1874. (doi:10.2337/dc10-2234)

27 Koopman LP, McCrindle BW, Slorach C, Chahal N, Hui W, Sarkola T, Manlhiot C, Jaeggi ET, Bradley TJ \& Mertens L. Interaction between myocardial and vascular changes in obese children: a pilot study. Journal of the American Society of Echocardiography 201225 401-410.e401. (doi:10.1016/j.echo.2011.12.018)

28 Juonala M, Viikari JS, Rönnemaa T, Helenius H, Taittonen L \& Raitakari OT. Elevated blood pressure in adolescent boys predicts endothelial dysfunction: the Cardiovascular Risk in Young Finns Study. Hypertension 200648 424-430. (doi:10.1161/01.HYP.0000237666. 78217.47)

29 Aggoun Y, Farpour-Lambert NJ, Marchand LM, Golay E, Maggio AB \& Beghetti M. Impaired endothelial and smooth muscle functions and arterial stiffness appear before puberty in obese children and are associated with elevated ambulatory blood pressure. European Heart Journal 200829 792-799. (doi:10.1093/eurheartj/ehm633)

30 Reaven GM. Role of insulin resistance in human disease. Diabetes 1988 37 1595-1607. (doi:10.2337/diab.37.12.1595)

31 Keskin M, Kurtoglu S, Kendirci M, Atabek M \& Yazici C. Homeostasis model assessment is more reliable than the fasting glucose/insulin ratio and quantitative insulin sensitivity check index for assessing insulin resistance among obese children and adolescents. Pediatrics 2005115 e500-e503. (doi:10.1542/peds.2004-1921)

32 Khoury M, Manlhiot C \& McCrindle B. Role of the waist/height ratio in the cardiometabolic risk assessment of children classified by body mass index. Journal of the American College of Cardiology 201362 742-751. (doi:10.1016/j.jacc.2013.01.026)

33 Agirbasli M, Agaoglu NB, Orak N, Caglioz H, Ocek T, Poci N, Salaj A \& Maya S. Sex hormones and metabolic syndrome in children and adolescents. Metabolism: Clinical and Experimental 200958 1256-1262. (doi:10.1016/j.metabol.2009.03.024)

34 Matthews DR, Hosker JP, Rudenski AS, Naylor BA, Treacher DF \& Turner RC. Homeostasis model assessment: insulin resistance and $\beta$-cell function from fasting plasma glucose and insulin concentrations in man. Diabetologia 198528 412-419. (doi:10.1007/BF00280883)

35 Guerrero-Romero F, Violante R \& Rodríguez-Morán M. Distribution of fasting plasma glucose and prevalence of impaired fasting glucose, impaired glucose tolerance and type 2 diabetes in the Mexican paediatric population. Paediatric and Perinatal Epidemiology 200923 363-369. (doi:10.1111/j.1365-3016.2009.01035.x)

36 Cruz M, Torres M, Aguilar-Herrera B, Perez-Johnston R, GuzmanJuarez N, Aranda M \& Kumate J. Type 2 diabetes mellitus in children - an increasing health problem in Mexico. Journal of Pediatric Endocrinology \& Metabolism 200417 183-190. (doi:10.1515/JPEM. 2004.17.2.183)

37 Hwang YC, Jee JH, Oh EY, Choi YH, Lee MS, Kim KW \& Lee MK. Metabolic syndrome as a predictor of cardiovascular diseases and type 2 diabetes in Koreans. International Journal of Cardiology 2009 134 313-321. (doi:10.1016/j.ijcard.2008.12.025)

38 Cheng P, Neugaard B, Foulis P \& Conlin PR. Hemoglobin A1c as a predictor of incident diabetes. Diabetes Care 201134 610-615. (doi:10.2337/dc10-0625)

39 Zimmet P, Alberti KG, Kaufman F, Tajima N, Silink M, Arslanian S, Wong G, Bennett P, Shaw J, Caprio S et al. The metabolic syndrome in children and adolescents - an IDF consensus report. Pediatric Diabetes 20078 299-306. (doi:10.1111/j.1399-5448.2007.00271.x)

40 Watts K, Beye P, Siafarikas A, O'Driscoll G, Jones TW, Davis EA \& Green DJ. Effects of exercise training on vascular function in obese children. Journal of Pediatrics 2004144 620-625. (doi:10.1016/j.jpeds. 2004.02.027)

Received in final form 4 September 2013

Accepted 15 October 2013 http://www.endocrineconnections.org DOI: 10.1530/EC-13-0057 (c) 2013 The authors Published by Bioscientifica Ltd

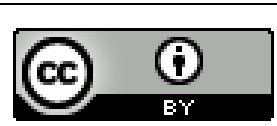

This work is licensed under a Creative Commons Attribution 3.0 Unported License. 